\title{
Pricing Currency Option in a Mixed Fractional Brownian Motion with Jumps Environment
}

\author{
Foad Shokrollahi and Adem Kılıçman \\ Department of Mathematics and Institute for Mathematical Research, University Putra Malaysia (UPM), \\ 43400 Serdang, Selangor, Malaysia \\ Correspondence should be addressed to Adem Kilıçman; akilic@upm.edu.my
}

Received 17 December 2013; Accepted 10 February 2014; Published 9 April 2014

Academic Editor: Abdon Atangana

Copyright (C) 2014 F. Shokrollahi and A. K1lıçman. This is an open access article distributed under the Creative Commons Attribution License, which permits unrestricted use, distribution, and reproduction in any medium, provided the original work is properly cited.

\begin{abstract}
A new framework for pricing the European currency option is developed in the case where the spot exchange rate fellows a mixed fractional Brownian motion with jumps. The jump mixed fractional partial differential equation is obtained. Some Greeks and properties volatility are discussed. Finally the numerical simulations illustrate that our model is flexible and easy to implement.
\end{abstract}

\section{Introduction}

A currency option is a contract, which gives the owner the right but not the obligation to purchase or sell the indicated amount of foreign currency at a specified price within a specified period of time (American Option) or on a fixed date (European Option). Since the currency option can be used as a tool for investment and hedging, it is one of the best tools for corporations or individuals to hedge against adverse movements in exchange rates. Thus in the present work the theoretical models for pricing currency options have been carried out.

Option pricing was introduced by Black-Scholes in 1973. However, Dravid et al. [1], Ho et al. [2], Toft and Reiner [3], and Kwok and Wong [4] also worked on that direction. Duan and Wei [5] indicated that option pricing by Black-Scholes model which is based on Brownian motion cannot illustrate clearly two phenomena from stock markets: first asymmetric leptokurtic features and second the volatility smile. In a work by Garman and Kohlhagen (Hereafter G-K) [6] was extended the Black-Scholes model in order to make valuation European currency option, having two fundamental features: (1) estimating the market volatility of an underlying asset generally as a function of price and time without direct reference to the specific investor characteristics such as expected yield, risk aversion measures, or utility functions; (2) selfreplicating strategy or hedging. However, some researchers (see [7]) presented some evidence of the mispriced currency options by the G-K model. The significant causes of why this model is not suitable for stock markets are that the currencies are different from the stocks in main respects and geometric Brownian motion cannot resolve the conduct of currency return; see [8]. Since then, in order to overcome these problems, many systems for pricing currency options were proposed by using amendments of the G-K model, such as, Rosenberg [9], Sarwar and Krehbiel [10], and Bollen and Rasiel [11].

However all these researches consider that the logarithmic returns of the exchange rate were independent and identically distributed normal random variables. Nevertheless, the experimental investigation on asset return shows that discontinuities or jumps are believed to be an indispensable element of financial stock pricing; see [12-17]. Merton, in [18], proposed a jump diffusion process with Poisson jump to match the abnormal fluctuations of stock price. Based on this theory, Kou [19], Cont and Tankov [20] also considered the problems of pricing options under a jump diffusion environment in a larger setting. Moreover, the empirical studies also demonstrated that the distributions of the logarithmic returns in the asset market generally reveal excess kurtosis 
with more probability mass around the origin and in the tails and less in the flanks than what would occur for normally distributed data [20]. It can be said that the properties of financial return series are nonnormal, nonindependent, and nonlinear, self-similar, with heavy tails, in both autocorrelations and cross-correlations, and volatility clustering [2132]. Since fractional Brownian motion has two substantial features such as self-similarity and long-range dependence, thus using it is more applicable to capture behavior from financial asset [32-37]. Although, the fractional Brownian motion is neither a Markov process nor a semimartingale, we cannot apply the common stochastic calculus to analyze it. Fortunately, Xiao et al. [38] employed the Wick product rather than the pathwise product to define a fractional stochastic integral whose mean is indeed zero. This property was very convenient for both theoretical developments and practical applications. Further, in [38], it was stated that if one uses the Wick-Ito-Skorohod integral, then can obtain an arbitrage-free model. Björk and Hult [39] showed recently that utilizing fractional Brownian motion in finance does not make much economic sense because, while Wick integration leads to no arbitrage, the definition of the corresponding self-financing trading strategies is quite restrictive, see for example [40], that is the simple buying-and-hold strategy is not self-financing. Therefore, the fractional market based on Wick integrals is considered which is a beautiful mathematical construction but with restricted applicability in finance.

From the above analysis one can conclude that the classical Ito calculus could not help in fractional Brownian motion and to describe an appropriate stochastic integral with respect to fractional Brownian motion is very strict. Indeed, the principal obstacle of applying fractional Brownian motion in finance is that it is not semimartingale. To capture this problem, to take into account the long memory property, and to get fluctuations form financial markets, it is suitable to apply the mixed fractional Brownian motion to take fluctuations from financial asset (see [41-44]). The mixed fractional Brownian motion is a family of Gaussian processes that is a linear combination of Brownian motion and fractional Brownian motion. It is considered as one of special class of long memory processes with Hurst parameter $H>1 / 2$. In economics the first work of using mixed fractional Brownian motion could be found in [45]. Moreover, Cheridito [45] had proved that, for $H \in(3 / 4,1)$, the mixed model with dependent Brownian motion and fractional Brownian motion is equivalent to one with Brownian motion and hence it was arbitrage-free. Recent further applications have been accepted in [46]. Throughout the present work, we follow the idea in [45]; that, is we will assume that $H \in$ $(3 / 4,1)$. Moreover, some empirical studies have proved that this hypothesis is useful and applicable; see [46-51].

Further, to capture jumps or discontinuities, fluctuations and to take into account the long memory property, combination of Poisson jumps and mixed fractional Brownian motion is introduced in this paper. The jump mixed fractional Brownian motion is based on the assumption that exchange rate returns are generated by a two-part stochastic process: (1) small, continuous price movements are generated by a mixed fractional Brownian motion and (2) large, infrequent price jumps are generated by a Poisson process (see [52]). This twopart process is intuitively appealing, as it is consistent with an impressive market in which major information arrives infrequently and randomly. In addition, this process may provide a description for empirically observed distributions of exchange rate changes that are skewed, leptokurtic, long memory and have fatter tails than comparable normal distributions and for the apparent nonstationarity of variance. Although, various models have been applied for pricing currency options, utilizing jump fractional Brownian motion to pricing currency options has not been investigated. Then we illustrate how to price European currency options using the G-K type model derived in a jump mixed fractional Brownian environment. The comparative results of our model and other available valuation models indicate that our model is easy to implement.

The rest of this paper is organized as follows. In Section 2, we briefly state the definitions and properties related to $\mathrm{mfBm}$ that will be used in forthcoming sections and we prove some results regarding the quasi-conditional expectation. We present an analytical pricing formula for European currency option in a mixed fractional Brownian motion with jumps environment, in Section 3. Section 4 deals with the jump mixed fractional partial differential equation and discussed some Greeks of this jump mixed model. In Section 5, we indicate how to use our model to price currency options by numerical simulations. The comparison of our jump mixed fractional Brownian motion model and traditional models is presented. Section 6 draws the concluding remarks.

\section{Preliminaries}

In this section we recall some definitions and results which we need for the rest of paper. This outcome can be found in $[45,46,53,54]$.

Definition 1. A mixed fractional Brownian motion of parameters $\alpha, \beta$, and $H$ is a linear combination of fractional Brownian motion with Hurst parameter $H$ and Brownian motion, defined on the probability $(\Omega, F, P)$ for any $t \in R_{+}$ by

$$
M_{t}^{H}=\alpha B_{t}+\beta B_{t}^{H},
$$

where $B_{t}$ is a Brownian motion, $B_{t}^{H}$ is an independent fractional Brownian motion with Hurst parameter $H \in(0,1)$, and $\alpha$ and $\beta$ are two real constants such that $(\alpha, \beta) \neq(0,1)$.

Now we list some properties in $[52,54]$ by the following propositions.

Proposition 2. The mixed fractional Brownian motion $M_{t}^{H}$ satisfies the following properties:

(i) $M_{t}^{H}$ is a centered Gaussian process and not a Markovian one, for $H \in(0,1) \backslash 1 / 2$;

(ii) $M_{0}^{H}=0 P$-almost surely; 
(iii) the covariation function of $M_{t}^{H}(\alpha, \beta)$ and $M_{t}^{H}(a, b)$ for any $t, s R_{+}$is given by

$\operatorname{Cov}\left(M_{t}^{H}, M_{s}^{H}\right)=\alpha^{2}(t \wedge s)+\frac{\beta}{2}\left(t^{2 H}+s^{2 H}-|t-s|^{2 H}\right)$,

where $\wedge$ denote the minimum of two numbers;

(iv) the increments of $M_{t}^{H}(\alpha, \beta)$ are stationary and mixedself similar for any $h>0$,

$$
M_{h t}^{H}(\alpha, \beta) \triangleq M_{t}^{H}\left(\alpha h^{1 / 2}, \beta h^{H}\right)
$$

where $\triangleq$ means "to some law";

(v) the increments of $M_{t}^{H}$ are positively correlated if $1 / 2<$ $H<1$, uncorrelated if $H=1 / 2$, and negative correlated if $0<H<1 / 2$;

(vi) the increments of $M_{t}^{H}$ are long range dependent if and only if $H>1 / 2$;

(vii) for all $t \in R_{+}$, one has

$$
\begin{aligned}
E[ & \left.\left(M_{t}^{H}(\alpha, \beta)\right)^{n}\right] \\
& = \begin{cases}0, & n=2 l+1, \\
\frac{(2 l) !}{2^{l} l !}\left(\alpha^{2} t+\beta^{2} t^{2 H}\right)^{l}, & n=2 l .\end{cases}
\end{aligned}
$$

Now, let $(\Omega, F, P)$ be a probability field such that $B_{t}$ is Brownian motion with respect to $P$ and $B_{t}^{H}$ is an independent fractional Brownian motion with respect to $P$. Now we present some results regarding the quasi-conditional expectation that we will need for the rest of the paper (see [16]).

Lemma 3. For every $0<t<T$ and $\sigma \in C$ one has

$$
\widetilde{E}_{t}\left[e^{\sigma\left(B_{T}+B_{T}^{H}\right)}\right]=e^{\sigma\left(B_{T}+B_{T}^{H}\right)+\left(\sigma^{2} / 2\right)(T-t)+\left(\sigma^{2} / 2\right)\left(T^{2 H}-t^{2 H}\right)},
$$

where $\widetilde{E}_{t}$ denotes the quasi-conditional expectation with respect to risk-neutral measure.

Proof. See [44].

Lemma 4. Let $f$ be a function such that $\widetilde{E}_{t}\left[f\left(B_{T}, B_{T}^{H}\right)\right]<\infty$. Then, for every $0<t \leq T$ and $\sigma \in C$, one has

$$
\begin{aligned}
& \widetilde{E}_{t}\left[f\left(\sigma B_{T}+\sigma B_{T}^{H}\right)\right] \\
& =\int_{R} \frac{1}{\sqrt{2 \pi\left[\sigma^{2}(T-t)+\sigma^{2}\left(T^{2 H}-t^{2 H}\right)\right]}} \\
& \quad \times \exp \left[-\frac{\left(x-\sigma B_{t}-\sigma B_{t}^{H}\right)^{2}}{2\left[\sigma^{2}(T-t)+\sigma^{2}\left(T^{2 H}-t^{2 H}\right)\right]}\right] f(x) d x .
\end{aligned}
$$

Let $f(x)=\mathbf{1}_{A}$; one can easily obtain the following corollary.

Proof. See [44].
Corollary 5. Let $A \in B(R)$. Then

$$
\begin{aligned}
\widetilde{E}_{t}\left[\mathbf{1}_{A}\left(\sigma B_{T}+\sigma B_{T}^{H}\right)\right] & \\
=\int_{R}( & \left(\exp \left[-\frac{\left(x-\sigma B_{t}-\sigma B_{t}^{H}\right)^{2}}{2\left[\sigma^{2}(T-t)+\sigma^{2}\left(T^{2 H}-t^{2 H}\right)\right]}\right]\right) \\
& \left.\times\left(\sqrt{2 \pi\left[\sigma^{2}(T-t)+\sigma^{2}\left(T^{2 H}-t^{2 H}\right)\right]}\right)^{-1}\right) \\
& \times \mathbf{1}_{A}(x) d x .
\end{aligned}
$$

Let $\theta, w \in R$. Now, one considers the process

$$
\begin{aligned}
Z_{t}^{*} & =\theta B_{t}^{*}+w\left(B_{t}^{H}\right)^{*} \\
& =\theta B_{t}+\theta^{2} t+w B_{t}^{H}+w^{2} t^{2 H}, \quad 0 \leq t \leq T .
\end{aligned}
$$

From the Girsanov theorem, there exists a measure $P^{*}$ such that $Z_{t}^{*}$ is a new mixed fractional Brownian motion. One will denote $E_{t}^{*}[\cdot]$ the quasi-conditional expectation with respect to $P^{*}$. Consider

$$
X_{t}=\exp \left(-\theta B_{t}-\frac{\theta^{2}}{2} t-w B_{t}^{H}-\frac{w^{2}}{2} t^{2 H}\right) .
$$

Proof. See [44].

Lemma 6. Let $f$ be a function such that $\widetilde{E}_{t}\left[f\left(\theta B_{t}+w B_{t}^{H}\right)\right] \leq$ $\infty$. Then for every $t \leq T$, one has

$$
\widetilde{E}_{t}^{*}\left[f\left(\theta B_{T}+w B_{T}^{H}\right)\right]=\frac{1}{X_{t}} \widetilde{E}_{t}\left[f\left(\theta B_{T}+w B_{T}^{H}\right) X_{T}\right] .
$$

Proof. See [44].

Theorem 7. The price at every time $t \in[0, T]$ of a bounded $F_{T}^{H}$-measurable claim $F \in L^{2}$ is given by

$$
F_{t}=e^{-r(T-t)} \widetilde{E}_{t}[F],
$$

where represents the constants risk-free interest rate.

Proof. See [44].

\section{Pricing Currency Options in Mixed Fractional Brownian Motion with Jumps}

The aim of this section is to derive the pricing formula for European currency options. The mixed fractional Brownian motion with jump model by combining the mixed fractional Brownian motion and jump process (see $[43,52])$ is obtained and some properties are analyzed.

To derive the new currency option pricing formula in a jump mixed fractional market. The following hypothesis will be provided:

(i) there is no transaction costs or taxes and all securities are perfectly divisible; 
(ii) security trading is continuous;

(iii) the short-term domestic interest rate $r_{d}$ and foreign interest rate $r_{f}$ are known and constant thought time;

(iv) there are no risk-free arbitrage opportunities.

Now consider a jump fractional Brownian motion BlackScholes currency market that has two investments:

(a) a money market account:

$$
d \Pi_{t}=r_{d} \Pi_{t} d t
$$

where $r_{d}$ represent the domestic interest rate;

(b) a stock whose price satisfies the following equation:

$$
\begin{array}{r}
d S_{t}=S_{t}\left(\mu-\lambda \mu_{J(t)}\right) d t+\sigma S_{t} d B_{t} \\
+\sigma S_{t} d B_{t}^{H}+S_{t}\left(e^{J(t)}-1\right) d N_{t}, \\
0<t \leq T, S_{0}=S>0,
\end{array}
$$

where $S_{t}$ denote the spot exchange rate at time $t$ of one unit of the foreign currency measured in the domestic currency; the drift $\mu$ and volatility $\sigma$ are supposed to be constants; $B_{t}^{H}$ is a fractional Brownian motion with Hurst parameter $H>3 / 4 ; N_{t}$ is a poisson process with rate $\lambda ; J(t)$ is jump size percent at time $t$ which is a sequence of independent identically distributed; and $\left(e^{J(t)}-1\right) \sim N\left(\mu_{J(t)}, \delta^{2}(t)\right)$. Moreover, all three sources of randomness, the fractional Brownian motion $B_{t}^{H}$, the poisson process $N_{t}$, and the jump size $e^{J(t)}-1$, are supposed to be independent.

By using the Ito formula, the solution for stochastic differential equation (13) is

$$
\begin{gathered}
S_{t}=S \prod_{i=1}^{N_{t}} e^{J\left(t_{i}\right)} \exp \left[\left(\mu-\lambda \mu_{J(t)}\right) t+\sigma B_{t}^{H}+\sigma B_{t}\right. \\
\left.-\frac{1}{2} \sigma^{2} t-\frac{1}{2} \sigma^{2} t^{2 H}\right] .
\end{gathered}
$$

Let $C\left(t, S_{t}\right)$ be the price of a European call currency option at time $t$ with strike price $K$ that matures at time $T$. Then we obtain the pricing formula for currency option by the following theorem.

Theorem 8. The price at every $t \in[0, T]$ of a European call currency option with strike price $K$ that matures at time $T$ is given by

$$
\begin{gathered}
C\left(t, S_{t}\right)=\sum_{n=0}^{\infty} \frac{e^{-\lambda(T-t)} \lambda^{n}(T-t)^{n}}{n !} \varepsilon_{n} \\
\times\left[S_{t} \prod_{i=1}^{n} e^{J\left(t_{i}\right)} e^{-\left(r_{f}+\lambda \mu_{J(t)}\right)(T-t)} N\left(d_{1}\right)\right. \\
\left.\quad-K e^{-r_{d}(T-t)} N\left(d_{2}\right)\right]
\end{gathered}
$$

where

$$
\begin{gathered}
d_{1}=\left(\ln \left(S_{t} \prod_{i=1}^{n} \frac{e^{J\left(t_{i}\right)}}{K}\right)\left(r_{d}-r_{f}-\lambda \mu_{J(t)}\right)(T-t)\right. \\
\left.+\frac{1}{2} \sigma^{2}(T-t)+\frac{1}{2} \sigma^{2}\left(T^{2 H}-t^{2 H}\right)\right) \\
\times\left(\sqrt{\sigma^{2}(T-t)+\sigma^{2}\left(T^{2 H}-t^{2 H}\right)}\right)^{-1}, \\
d_{2}=d_{1}-\sqrt{\sigma^{2}(T-t)+\sigma^{2}\left(T^{2 H}-t^{2 H}\right)},
\end{gathered}
$$

$\varepsilon_{n}$ denote the expectation operator over the distribution of $\prod_{i=1}^{n} e^{J\left(t_{i}\right)}$, and $N(\cdot)$ is the cumulative normal distribution. In addition, we can calculate price of a put currency option which is made by the following corollary.

Corollary 9. The price at every $t \in[0, T]$ of a European put currency option with strike price $K$ and maturity $T$ is given by

$$
\begin{aligned}
P\left(t, S_{t}\right)= & \sum_{n=0}^{\infty} \frac{e^{-\lambda(T-t)} \lambda^{n}(T-t)^{n}}{n !} \varepsilon_{n} \\
\times & {\left[K e^{-r_{d}(T-t)} N\left(-d_{2}\right)\right.} \\
& \left.\quad-S_{t} \prod_{i=1}^{n} e^{J\left(t_{i}\right)} e^{-\left(r_{f}+\lambda \mu_{J(t)}\right)(T-t)} N\left(-d_{1}\right)\right],
\end{aligned}
$$

where

$$
\begin{gathered}
d_{1}=\left(\ln \left(S_{t} \prod_{i=1}^{n} \frac{e^{J\left(t_{i}\right)}}{K}\right)\left(r_{d}-r_{f}-\lambda \mu_{J(t)}\right)(T-t)\right. \\
\left.+\frac{1}{2} \sigma^{2}(T-t)+\frac{1}{2} \sigma^{2}\left(T^{2 H}-t^{2 H}\right)\right) \\
\times\left(\sqrt{\sigma^{2}(T-t)+\sigma^{2}\left(T^{2 H}-t^{2 H}\right)}\right)^{-1}, \\
d_{2}=d_{1}-\sqrt{\sigma^{2}(T-t)+\sigma^{2}\left(T^{2 H}-t^{2 H}\right)} .
\end{gathered}
$$

\section{Property of Pricing Formula}

Assume that $V$ is the value of a whole portfolio of different option. The value of whole portfolio satisfies in the jump mixed fractional Black-Scholes partial differential equation that present in this theorem. 
Theorem 10. The price of a currency option with a bounded payoff $f\left(S_{t}\right)$ is given by $V\left(S_{t}, t\right)$, where $V\left(S_{t}, t\right)$ is the solution of the PDE:

$$
\begin{aligned}
\frac{\partial V}{\partial t}+ & \frac{1}{2} \sigma^{2} S^{2} \frac{\partial^{2} V}{\partial S^{2}}+H \sigma^{2} t^{2 H-1} S^{2} \frac{\partial^{2} V}{\partial S^{2}} \\
& +\left(r_{d}-r_{f}-\lambda \mu_{J(t)}\right) S \frac{\partial V}{\partial S}-r_{d} V \\
& +\lambda E\left[V\left(e^{J(t)} S_{t}, t\right)-V\left(S_{t}, t\right)\right]=0 .
\end{aligned}
$$

Now, we discuss the properties of jump mixed fractional Brownian motion such as Greeks which are basic tools in risk management and trading options without the knowledge of Greeks can result in high loses.

Theorem 11. Suppose $C=C\left(t, S_{t}\right)$ be the price of European call currency option the Greeks are given by

$$
\begin{aligned}
& \Delta=\frac{\partial C}{\partial S}=\sum_{n=0}^{\infty} \frac{e^{-\lambda(T-t)} \lambda^{n}(T-t)^{n}}{n !} \varepsilon_{n} \\
& \times\left[\prod_{i=1}^{n} e^{J\left(t_{i}\right)} e^{-\left(r_{f}+\lambda \mu_{J(t)}\right)(T-t)} N\left(d_{1}\right)\right] . \\
& \nabla=\frac{\partial C}{\partial K}=\sum_{n=0}^{\infty} \frac{e^{-\lambda(T-t)} \lambda^{n}(T-t)^{n}}{n !} \\
& \times \varepsilon_{n}\left[-e^{-r_{d}(T-t)} N\left(d_{2}\right)\right] . \\
& \rho_{r_{d}}=\frac{\partial C}{\partial r_{d}}=\sum_{n=0}^{\infty} \frac{e^{-\lambda(T-t)} \lambda^{n}(T-t)^{n}}{n !} \\
& \times \varepsilon_{n}\left[K(T-t) e^{-r_{d}(T-t)}\right] N\left(d_{2}\right) . \\
& \rho_{r_{f}}=\frac{\partial C}{\partial r_{f}}=\sum_{n=0}^{\infty} \frac{e^{-\lambda(T-t)} \lambda^{n}(T-t)^{n}}{n !} \\
& \times \varepsilon_{n}\left[-S_{t}(T-t) \prod_{i=1}^{n} e^{J\left(t_{i}\right)}\right. \\
& \left.\times e^{-\left(r_{f}+\lambda \mu_{J(t)}\right)(T-t)} N\left(d_{1}\right)\right] . \\
& \Theta=\frac{\partial C}{\partial t}=\sum_{n=0}^{\infty}\left(e^{-\lambda(T-t)} \lambda^{n+1}(T-t)^{n}\right. \\
& \left.-n e^{\lambda(T-t)} \lambda^{n}(T-t)^{n-1}\right)(n !)^{-1} \varepsilon_{n} \\
& \times\left[S_{t} \prod_{i=1}^{n} e^{J\left(t_{i}\right)} e^{-\left(r_{f}+\lambda \mu_{J(t)}\right)(T-t)} N\left(d_{1}\right)\right] \\
& -K e^{-r_{d}(T-t)} N\left(d_{2}\right)+\sum_{n=0}^{\infty} \frac{e^{-\lambda(T-t)} \lambda^{n}(T-t)^{n}}{n !} \varepsilon_{n} \\
& \times\left[\left(r_{f}+\lambda \mu_{J(t)}\right) S_{t} \prod_{i=1}^{n} e^{J\left(t_{i}\right)} e^{-\left(r_{f}+\lambda \mu_{J(t)}\right)(T-t)} N\left(d_{1}\right)\right]
\end{aligned}
$$

$$
\begin{gathered}
-r_{d} K e^{-r_{d}(T-t)} N\left(d_{2}\right) \\
-\frac{1}{2} \frac{\sigma^{2}+2 H \sigma^{2} t^{2 H-1}}{\sqrt{\sigma^{2}(T-t)+\sigma^{2}\left(T^{2 H}-t^{2 H}\right)}} \\
\times S_{t} \prod_{i=1}^{n} e^{J\left(t_{i}\right)} e^{-\left(r_{f}+\lambda \mu_{J(t)}\right)(T-t)} N^{\prime}\left(d_{1}\right) . \\
\frac{\partial^{2} C}{\partial S^{2}}=\sum_{n=0}^{\infty} \frac{e^{-\lambda(T-t)} \lambda^{n}(T-t)^{n}}{n !} \\
\times \varepsilon_{n}\left[\frac{\prod_{i=1}^{n} e^{J\left(t_{i}\right)} e^{-\left(r_{f}+\lambda \mu_{J}(t)\right)(T-t)}}{v_{t} \sqrt{\sigma^{2}(T-t)+\sigma^{2}\left(T^{2 H}-t^{2 H}\right)}} N^{\prime}\left(d_{1}\right)\right. \\
=\frac{\partial C}{\partial \sigma}=\sum_{n=0}^{\infty} \frac{e^{-\lambda(T-t)} \lambda^{n}(T-t)^{n}}{n !} \varepsilon_{n} \\
\times\left[\begin{array}{l}
S_{t} \prod_{i=1}^{n} e^{J\left(t_{i}\right)} e^{-\left(r_{f}+\lambda \mu_{J(t)}\right)(T-t)} \\
\times \frac{\sigma(T-t)+\sigma\left(T^{2 H}-t^{2 H}\right)}{\sqrt{\sigma^{2}(T-t)+\sigma^{2}\left(T^{2 H}-t^{2 H}\right)}} N^{\prime}\left(d_{1}\right)
\end{array}\right]
\end{gathered}
$$

The following theorem represents the influence of Hurst parameter $H$ in jump mixed fractional Brownian motion.

Theorem 12. The influence of the Hurst parameter can be written as

$$
\begin{aligned}
\frac{\partial C}{\partial H}= & \sum_{n=0}^{\infty} \frac{e^{-\lambda(T-t)} \lambda^{n}(T-t)^{n}}{n !} \varepsilon_{n} \\
& \times\left[S_{t} \frac{\sigma^{2}\left(T^{2 H} \ln T-t^{2 H} \ln t\right)}{\sqrt{\sigma^{2}(T-t)+\sigma^{2}\left(T^{2 H}-t^{2 H}\right)}}\right. \\
& \left.\times \prod_{i=1}^{n} e^{J\left(t_{i}\right)} e^{-\left(r_{f}+\lambda \mu_{J(t)}\right)(T-t)} N^{\prime}\left(d_{1}\right)\right] .
\end{aligned}
$$

Suppose the forward price of an exchange rate is as

$$
\begin{gathered}
f \triangleq S(t) \prod_{i=1}^{n} e^{J\left(t_{i}\right)} e^{\left(r_{d}-r_{f}-\lambda \mu_{J(t)}\right)(T-t)} \\
d_{ \pm}=\frac{\ln (f / K) \pm\left(\sigma^{2} / 2\right)\left(T^{2 H}-t^{2 H}\right) \pm\left(\sigma^{2} / 2\right)(T-t)}{\sigma \sqrt{T^{2 H}-t^{2 H}+T-t}} .
\end{gathered}
$$

Remark 13. The relationship of call-put parity satisfies as

$$
C\left(t, S_{t}\right)-P\left(t, S_{t}\right)=S_{t} e^{-\left(r_{f}+\lambda \mu_{J(t)}\right)(T-t)}-K e^{-r_{d}(T-t)} .
$$


TABLE 1: The valuation of chosen parameters used in these models.

\begin{tabular}{lcccccccc}
\hline Model type & $r_{d}$ & $r_{f}$ & $\sigma$ & $K$ & $H$ & $J$ & $\lambda$ & $\mu_{J}$ \\
\hline G-K & 0.0210 & 0.0320 & 0.1050 & 100 & - & - & - & - \\
PFBM & 0.0210 & 0.0320 & 0.1050 & 100 & 0.76 & - & - & - \\
PMFBM & 0.0210 & 0.0320 & 0.1050 & 100 & 0.76 & - & - & - \\
JMFBM & 0.0210 & 0.0320 & 0.1050 & 100 & 0.76 & 0.008 & 2.3 & 0.00065 \\
JMFBM & 0.0210 & 0.0320 & 0.1050 & 100 & 0.76 & 0.0031 & 7.3 & -0.00065 \\
\hline
\end{tabular}

This is just more complicated way to write the trivial equation $S_{t}=S_{t}^{+}-S_{t}^{-}$.

Remark 14. The relationship of put-call parity can be written as

$$
\frac{\partial C\left(t, S_{t}\right)}{\partial S_{t}}-\frac{\partial P\left(t, S_{t}\right)}{\partial S_{t}}=e^{-\left(r_{f}+\lambda \mu_{J(t)}\right)(T-t)}
$$

\section{Simulation Studies}

This section indicate how to performance our jump mixed fractional Brownian motion model and to illustrate the effects of jump parameters of our pricing model. For these aims, we report on two sets of numerical experiments. In the first set, we compare theoretical prices of some assumptive options among of the following models: the G-K, the pure fractional Brownian motion (hereafter PFBM), the pure mixed fractional Brownian motion (hereafter PMFBM), and our jump mixed fractional Brownian motion (hereafter JMFBM). These tests will not be based on empirical data, but they will consist of some simulations of different pricing models with some chosen parameters of some simulations of different pricing models with some chosen parameters that will not be based on empirical data. The second set shows the influence of different parameters of JMFBM. The code line is written in MATLAB.

5.1. Comparison of Option Prices. Now, for description of discrepancies among these methods: the G-K, the PFBM, the PMFBM, and our JMFBM methods, we present the theoretical prices of some assumptive options applying several models. All parameters which are needed for computing the assumptive currency call options present by the G-K, PFBM, PMFBM, and JMFBM methods are present in Table 1, respectively. The fourth and fifth line, which has low and high jump parameters, respectively, provides the parameters for calculating the prices by the JMFBM method. Tables 2 and 3 present the prices computed by different models, where $S$ denotes the price of exchange rate; $P_{\mathrm{G}-\mathrm{K}}$ denotes the prices calculated by the G-K method; $P_{\mathrm{P}-\mathrm{F}}$ shows the prices calculated by the PFBM; $P_{\mathrm{P}-\mathrm{MF}}$ indicates the prices simulated corresponding to PMFBM; and $P_{\mathrm{J}-\mathrm{MF}}$ shows the prices calculated by the JMFBM.

By comparing columns $P_{\mathrm{G}-\mathrm{K}}, P_{\mathrm{P}-\mathrm{F}}, P_{\mathrm{P}-\mathrm{MF}}$, and $P_{\mathrm{J}-\mathrm{MF}}^{*, a}$ in Tables 2 and 3 for the small maturity cases, we can conclude that the option prices given by four assessment methods almost are the same. The main reason in this case is that jump parameters are very small. Furthermore, the prices obtained by MFBM and JMFBM with small parameters in high and low expiration are close, since the jump parameters are very small. Also, Tables 2 and 3 show that the parameters in column $P_{\mathrm{J}-\mathrm{MF}}^{*, a}$ are greater than prices which is obtained by the G-K, PFBM, and MFBM. Next, the prices of assumptive options are investigated in large jump parameters case. Whenever the expiration time increases, the discrepancy among values calculated by JMFBM model and other models increases in large jump parameters case. Tables 2 and 3 show this result by comparing columns $P_{\mathrm{G}-\mathrm{K}}, P_{\mathrm{P}-\mathrm{F}}, P_{\mathrm{P}-\mathrm{MF}}$, and $P_{\mathrm{J}-\mathrm{MF}}^{*, b}$ for the small and large time to maturity cases. The findings from the columns $P_{\mathrm{G}-\mathrm{K}}, P_{\mathrm{P}-\mathrm{F}}$, $P_{\mathrm{J}-\mathrm{MF}}^{*, b}$, and $P_{\mathrm{P}-\mathrm{MF}}$ with $S \in[80,140]$ indicate that the amount of discrepancy proportion in prices is larger for out-of-themoney options in the large expiration time case and this discrepancy proportion declines with the increase the exchange rate.

5.2. The Influence of Parameters. In what follows, the value of call currency options is displayed by using JMFBM for different parameters. We just investigate the out-of-themoney case. In fact, the other cases in-the-money and atthe-money can also be consideres by applying the same method. Now, we consider the values of our jump mixed fractional Brownian motion currency options for various Hurst parameters $H$ and then investigate the values for different jump parameters. Figure 1 shows the values of call currency option against its parameters, $H, \lambda$, and $\mu_{J}$. The defaulting parameters are $S=90, K=100, r_{d}=0.0210$, $r_{f}=0.320, \sigma=0.1050, t=0, T=2, H=0.76$, $J=0.0031, \lambda=7.3, \mu_{J}=-0.00065$, and $\delta=0.0018$. No wonder that Figure 1 shows that (1) the option value is a decreasing function of $\mu_{J}, \delta$ and (2) increasing parameter of $H$ and $\lambda$ comes along with an increase of the option value.

Now, we compare the three prices derived from the GK, PFBM, and JMFBM models for out-of-the-money. These simulation parameters are selected: $S=89.8, r_{d}=0.0210$, $r_{f}=0.0320, \sigma=0.1050, H=0.76, J=0.008, \lambda=2.3$, $\mu_{j}=0.00065$, and $t=0.1$ with different exercise price $K \in[90,120]$ and expiration $T \in[0.11,10]$. For out-of-themoney Figure 2 indicates the option price discrepancies by the G-K, PMFBM, and JMFBM methods, respectively. From the figures it is concluded that the prices by JMFBM are better fitted to the G-K model. Therefore, we can see that our JMFBM seems reasonable. 
TABLE 2: Results by different pricing models.

\begin{tabular}{|c|c|c|c|c|c|}
\hline \multirow{2}{*}{$S$} & \multicolumn{5}{|c|}{ Low time to maturity, $T=0.5, t=0$} \\
\hline & $P_{\mathrm{G}-\mathrm{K}}$ & $P_{P-F}$ & $P_{P-\mathrm{MF}}$ & $P_{J-\mathrm{MF}}^{*, \mathrm{a}}$ & $P_{J-\mathrm{MF}}^{*, \mathrm{~b}}$ \\
\hline 80 & 0.0019 & 0.0001 & 0.0259 & 0.0348 & 0.0399 \\
\hline 85 & 0.0275 & 0.0058 & 0.1469 & 0.1865 & 0.2094 \\
\hline 90 & 0.2068 & 0.0854 & 0.5664 & 0.6857 & 0.7550 \\
\hline 95 & 0.9124 & 0.5814 & 1.6014 & 1.8636 & 2.0158 \\
\hline 98 & 1.8093 & 1.3654 & 2.6454 & 3.0172 & 3.2325 \\
\hline 100 & 2.6590 & 2.1788 & 3.5415 & 3.9912 & 4.2510 \\
\hline 102 & 3.7188 & 3.2429 & 4.5993 & 5.1273 & 5.4313 \\
\hline 110 & 9.7210 & 9.5097 & 10.2519 & 11.0509 & 11.5015 \\
\hline 120 & 19.1629 & 19.1441 & 19.2787 & 20.2763 & 20.8171 \\
\hline 130 & 28.9816 & 28.9811 & 28.9944 & 30.1055 & 30.6812 \\
\hline 140 & 38.8223 & 38.8223 & 38.8232 & 40.0284 & 40.6266 \\
\hline
\end{tabular}

* The maximum number of iteration is 100 .

${ }^{a}$ The parameters for calculations are in the third line of Table 1.

${ }^{b}$ The parameters for calculations are in the forth line of Table 1.

TABLE 3: Results by different pricing models.

\begin{tabular}{|c|c|c|c|c|c|}
\hline \multirow{2}{*}{$S$} & \multicolumn{5}{|c|}{ Low time to maturity, $T=2, t=0$} \\
\hline & $P_{\mathrm{G}-\mathrm{K}}$ & $P_{P-F}$ & $P_{P-\mathrm{MF}}$ & $P_{J-\mathrm{MF}}^{*, \mathrm{a}}$ & $P_{J-\mathrm{MF}}^{*, \mathrm{~b}}$ \\
\hline 80 & 0.2589 & 0.5780 & 1.4574 & 1.9778 & 2.3126 \\
\hline 85 & 0.6657 & 1.2020 & 2.4403 & 3.2183 & 3.7063 \\
\hline 90 & 1.4466 & 2.2186 & 3.7983 & 4.8833 & 5.5476 \\
\hline 95 & 2.7384 & 3.7120 & 5.5627 & 6.9919 & 7.8466 \\
\hline 98 & 3.7991 & 4.8557 & 6.8209 & 8.4684 & 9.4401 \\
\hline 100 & 4.6315 & 5.7272 & 7.7420 & 9.5380 & 10.5878 \\
\hline 102 & 5.5643 & 6.6810 & 8.7277 & 10.6735 & 11.8008 \\
\hline 110 & 10.2397 & 11.2873 & 13.2787 & 15.8219 & 17.2446 \\
\hline 120 & 17.7735 & 18.5190 & 20.1458 & 23.3889 & 25.1289 \\
\hline 130 & 26.4100 & 26.8349 & 27.9874 & 31.8470 & 33.8372 \\
\hline 140 & 35.5361 & 35.7410 & 36.4750 & 40.8680 & 43.9468 \\
\hline
\end{tabular}

* The maximum number of iteration is 100 .

${ }^{\mathrm{a}}$ The parameters for calculations are in the third line of Table 1.

${ }^{b}$ The parameters for calculations are in the forth line of Table 1.

\section{Conclusions}

This paper compounds the jump process and mixed fractional Brownian motion. Furthermore, some particular features of currency pricing formula are also indicated. Furthermore, experimental results obtained in Section 5 indicate that when the expiration date is great sufficient the JMFBM model is essential to use. However, our jump mixed fractional Brownian motion model is simple to employ and has the especial properties to describe the unusual movements of financial markets. In conclusion, since mixed fractional Brownian motion is a suitable mathematical model of profoundly correlated random processes and jumps are undeniable component in financial markets, jump mixed fractional Brownian model will be a more appropriate method for pricing currency options.

\section{Appendix}

Proof of Theorem 8. In a risk natural world, from Theorem 7, a European call currency option with maturity $T$ and strike price $K$ can be displayed as

$$
\begin{aligned}
C\left(t, S_{t}\right)= & \widetilde{E}_{\widehat{P}_{H}}\left[e^{-r_{d}(T-t)}\left(S_{T}-K\right)^{+} \mid F_{t}^{H}\right] \\
= & e^{-r_{d}(T-t)} \widetilde{E}_{\widehat{P}_{H}}\left[S_{T} \mathbf{1}_{S_{T}>K} \mid F_{t}^{H}\right] \\
& -K e^{-r_{d}(T-t)} \widetilde{E}_{\widehat{P}_{H}}\left[\mathbf{1}_{S_{T}>K} F_{t}^{H}\right],
\end{aligned}
$$

where $\mathbf{1}_{S_{T}>K}$ is an indicator function.

Let

$$
\widehat{B}_{t}+\widehat{B}_{t}^{H}=\frac{\mu-\lambda \mu_{J(t)}+r_{f}-r_{d}}{\sigma} t+B_{t}+B_{t}^{H} .
$$



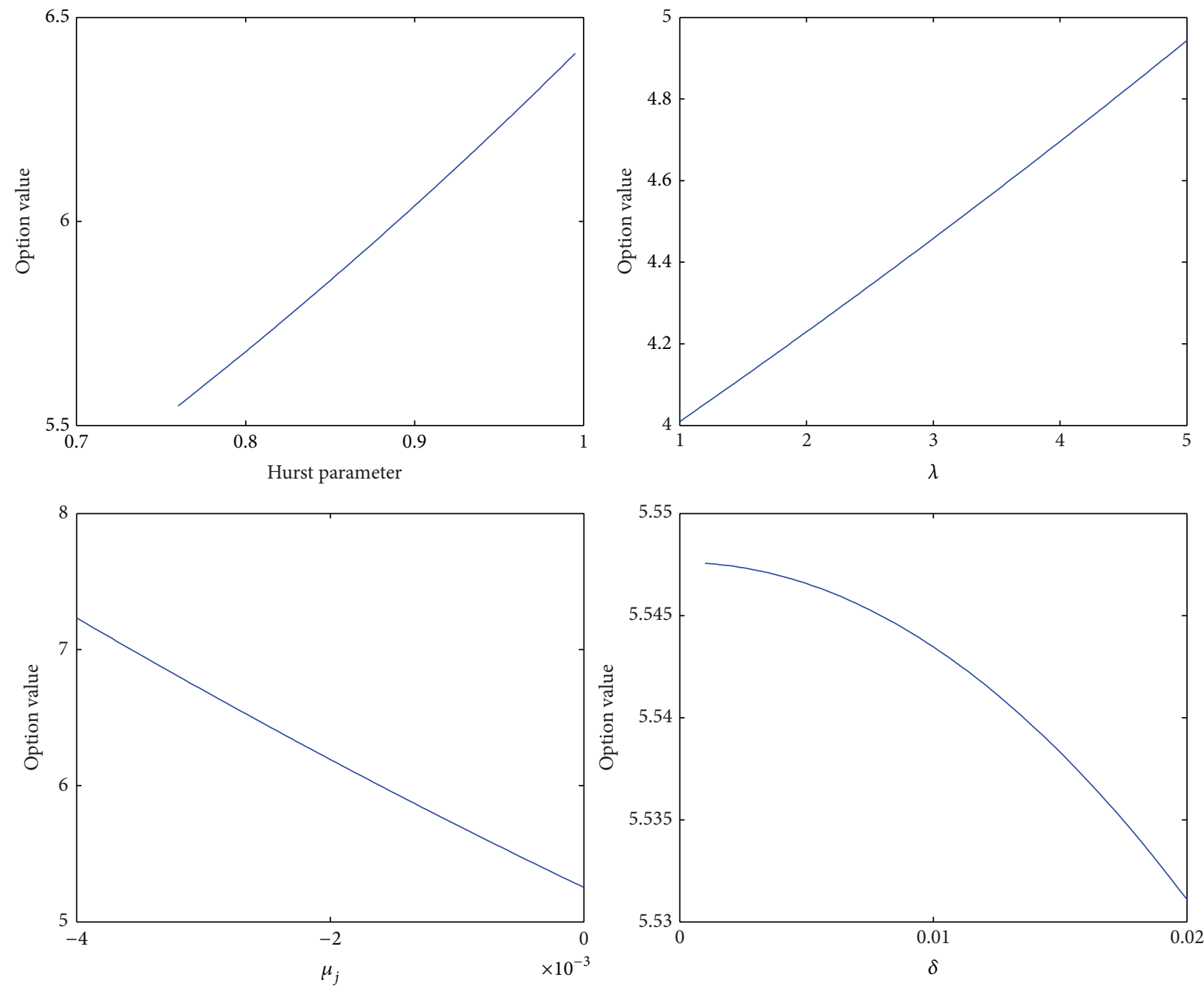

Figure 1: Value of the currency call option.

Then we obtain

$$
\begin{aligned}
S_{T}=S_{t} \prod_{i=1}^{N_{T-t}} \exp \left[\left(\mu-\lambda \mu_{J(t)}\right)(T-t)+\sigma\left(\widehat{B}_{T}^{H}-\widehat{B}_{t}^{H}\right)\right. \\
\left.+\sigma\left(\widehat{B}_{T}-\widehat{B}_{t}\right)\right] \\
\times\left[-\frac{1}{2} \sigma^{2}(T-t)-\frac{1}{2} \sigma^{2}\left(T^{2 H}-t^{2 H}\right)\right] .
\end{aligned}
$$

Let

$$
\begin{gathered}
S_{T}^{n}=S_{t} \prod_{i=1}^{n} \exp \left[\left(\mu-\lambda \mu_{J(t)}\right)(T-t)+\sigma\left(\widehat{B}_{T}^{H}-\widehat{B}_{t}^{H}\right)\right. \\
\left.+\sigma\left(\widehat{B}_{T}-\widehat{B}_{t}\right)\right] \\
\times\left[-\frac{1}{2} \sigma^{2}(T-t)-\frac{1}{2} \sigma^{2}\left(T^{2 H}-t^{2 H}\right)\right] .
\end{gathered}
$$

By using the fractional Girsanov theorem, we obtain that $\widehat{B}_{t}^{H}-\widehat{B}_{t}$ is a new mixed fractional Brownian motion under $\widehat{P}_{H}$. Hence, setting

$$
\begin{aligned}
d_{2}^{*}= & \ln \left[\frac{K}{S_{t} \prod_{i=1}^{n} e^{J\left(t_{i}\right)}}\right]-\left(r_{d}-r_{f}-\lambda \mu_{J(t)}\right)(T-t) \\
& +\sigma\left(\widehat{B}_{t}^{H}+\widehat{B}_{t}\right)+\frac{1}{2} \sigma^{2}\left(T^{2 H}-t^{2 H}\right)+\frac{1}{2} \sigma^{2}(T-t)
\end{aligned}
$$




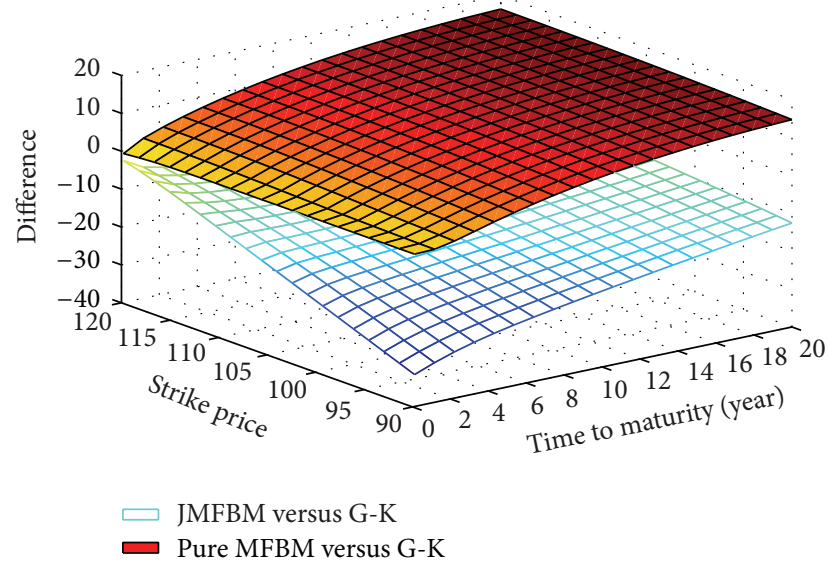

FIGURE 2: Relative difference among the G-K model, PMFBM, and JMFBM for out-of-the-money.

and using Theorem 7 we derive that

$$
\begin{aligned}
& \widetilde{E}_{\widehat{P}_{H}}\left[\mathbf{1}_{S_{T}>K} \mid F_{t}^{H}\right] \\
& =\widetilde{E}_{\widehat{P}_{H}}\left[\mathbf{1}_{d_{2}^{*}<\sigma\left(\widehat{B}_{T}^{H}+\widehat{B}_{T}\right)<\infty} \mid F_{t}^{H}\right] \\
& =\int_{d_{2}^{*}}^{\infty} \frac{1}{\sqrt{2 \pi\left[\sigma^{2}(T-t)+\sigma^{2}\left(T^{2 H}-t^{2 H}\right)\right]}} \\
& \times \exp \left[-\frac{\left(x-\sigma \widehat{B}_{t}^{H}-\sigma \widehat{B}_{t}\right)^{2}}{2\left[\sigma^{2}(T-t)+\sigma^{2}\left(T^{2 H}-t^{2 H}\right)\right]}\right] d x \\
& =\int_{-\infty}^{\left(\sigma \widehat{B}_{t}^{H}+\widehat{B}_{t}-d_{2}^{*}\right) / \sqrt{\sigma^{2}(T-t)+\sigma^{2}\left(T^{2 H}-t^{2 H}\right)}} \frac{1}{\sqrt{2 \pi}} e^{-z^{2} / 2} d z=N\left(d_{2}\right),
\end{aligned}
$$

where

$$
\begin{aligned}
d_{2}= & \frac{\sigma \widehat{B}_{t}^{H}+\sigma \widehat{B}_{t}-d_{2}^{*}}{\sqrt{\sigma^{2}(T-t)+\sigma^{2}\left(T^{2 H}-t^{2 H}\right)}} \\
= & \left(\ln \left(S_{t} \prod_{i=1}^{n} \frac{e^{J\left(t_{i}\right)}}{K}\right)+\left(r_{d}-r_{f}-\lambda \mu_{J(t)}\right)(T-t)\right. \\
& \left.-\frac{1}{2} \sigma^{2}\left(T^{2 H}-t^{2 H}\right)-\frac{1}{2} \sigma^{2}(T-t)\right) \\
& \times\left(\sqrt{\sigma^{2}(T-t)+\sigma^{2}\left(T^{2 H}-t^{2 H}\right)}\right)^{-1} .
\end{aligned}
$$

Now, we consider $\widetilde{E}_{\widehat{P}_{H}}\left[S_{T} \mathbf{1}_{S_{T}>K} \mid F_{t}^{H}\right]$; setting

$$
\sigma B_{t}^{*}+\sigma\left(B_{t}^{H}\right)^{*}=\sigma\left(\widehat{B}_{t}-\sigma t\right)+\sigma\left(\widehat{B}_{t}^{H}-\sigma t^{2 H}\right)
$$

from the fractional Girsanov formula we know that there exists a probability measure $P_{H}^{*}$ in which $\sigma B_{t}^{*}+\sigma\left(B_{t}^{H}\right)^{*}$ is a new MFBM. Let

$$
X_{t}=\exp \left(\sigma \widehat{B}_{t}^{H}+\sigma \widehat{B}_{t}-\frac{1}{2} \sigma^{2} t^{2 H}-\frac{1}{2} \sigma^{2} t\right)
$$

then $S_{T}=S_{t} e^{\left(r_{d}-r_{f}\right)(T-t)} X_{T}$ from Lemma 6 and Theorem 7, we obtain that

$$
\begin{aligned}
\widetilde{E}_{\widehat{P}_{H}} & {\left[S_{T} \mathbf{1}_{S_{T}>K} \mid F_{t}^{H}\right] } \\
= & S_{t} e^{\left(r_{d}-r_{f}\right)(T-t)} \\
& \times \widetilde{E}_{\widehat{P}_{H}}\left[X_{T} \mathbf{1}_{d_{2}^{*}<\sigma \widehat{B}_{t}^{H}+\sigma \widehat{B}_{t}<+\infty}\left(\sigma \widehat{B}_{t}^{H}+\sigma \widehat{B}_{t}\right) \mid F_{t}^{H}\right] \\
= & S_{t} e^{\left(r_{d}-r_{f}\right)(T-t)} \\
& \times \widetilde{E}_{P_{H}^{*}}\left[\mathbf{1}_{d_{1}^{*}<\sigma\left(B_{T}^{H}\right)^{*}+\sigma B_{T}^{*}<+\infty}\left(\sigma\left(B_{T}^{H}\right)^{*}+\sigma B_{T}^{*}\right) \mid F_{t}^{H}\right] \\
= & S_{t} e^{\left(r_{d}-r_{f}\right)(T-t)} \\
& \times \int_{-\infty}^{\left(\sigma\left(B_{t}^{H}\right)^{*}+\sigma B_{t}^{*}-d_{1}^{*}\right) / \sqrt{\sigma^{2}(T-t)+\sigma^{2}\left(T^{2 H}-t^{2 H}\right)}} \frac{1}{\sqrt{2 \pi}} e^{-z^{2} / 2} d z \\
= & S_{t} e^{\left(r_{d}-r_{f}\right)(T-t)} N\left(d_{1}\right),
\end{aligned}
$$

where

$$
\begin{aligned}
d_{1}^{*}= & \ln \left(\frac{K}{S_{t} \prod_{i=1}^{n} e^{J\left(t_{i}\right)}}\right)-\left(r_{d}-r_{f}-\mu_{J(t)}\right)(T-t) \\
& +\sigma\left(B_{t}^{H}\right)^{*}+\sigma B_{t}^{*}-\frac{1}{2} \sigma^{2}(T-t) \\
& -\frac{1}{2} \sigma^{2}\left(T^{2 H}-t^{2 H}\right) \\
d_{1}= & \frac{\sigma\left(B_{t}^{H}\right)^{*}+\sigma B_{t}^{*}-d_{1}^{*}}{\sqrt{\sigma^{2}(T-t)+\sigma^{2}\left(T^{2 H}-t^{2 H}\right)}} \\
= & \left(\frac{K}{\ln \left(\frac{K}{S_{t} \prod_{i=1}^{n} e^{J\left(t_{i}\right)}}\right)-\left(r_{d}-r_{f}-\mu_{J(t)}\right)(T-t)}\right. \\
& \left.+\frac{1}{2} \sigma^{2}(T-t)+\frac{1}{2} \sigma^{2}\left(T^{2 H}-t^{2 H}\right)\right) \\
& \times\left(\sqrt{\sigma^{2}(T-t)+\sigma^{2}\left(T^{2 H}-t^{2 H}\right)}\right)^{-1} .
\end{aligned}
$$


From the analysis above and Theorem 2.2 from [55] it is calculated that the price of European call currency option can be written as

$$
\begin{gathered}
C\left(t, S_{t}\right)=\sum_{n=0}^{\infty} \frac{e^{-\lambda(T-t)} \lambda^{n}(T-t)^{n}}{n !} \\
\times \varepsilon_{n}\left[S_{t} \prod_{i=1}^{n} e^{J\left(t_{i}\right)} e^{-\left(r_{f}+\lambda \mu_{(t)}\right)(T-t)} N\left(d_{1}\right)\right. \\
\left.-K e^{-r_{d}(T-t)} N\left(d_{2}\right)\right]
\end{gathered}
$$

and for the price of put currency option

$$
\begin{aligned}
P\left(t, S_{t}\right)=\sum_{n=0}^{\infty} \frac{e^{-\lambda(T-t)} \lambda^{n}(T-t)^{n}}{n !} & \\
\times \varepsilon_{n}[ & K e^{-r_{d}(T-t)} N\left(-d_{2}\right) \\
& -S_{t} \prod_{i=1}^{n} e^{J\left(t_{i}\right)} e^{-\left(r_{f}+\lambda \mu_{J(t)}\right)(T-t)} \\
& \left.\times N\left(-d_{1}\right)\right] .
\end{aligned}
$$

Proof of Theorem 10. Let $V\left(t, S_{t}\right)$ be the price of the currency derivatives at time $t$ and let $\Pi$ be the portfolio value. Then we have

$$
\Pi_{t}=V\left(S_{t}, t\right)-\Delta S_{t} .
$$

Portfolio value changes in a very short period of time. Hence $d \Pi_{t}=d V\left(S_{t}, t\right)-\Delta S_{t}$ since

$$
\begin{gathered}
S_{t}=S \exp \left[\left(\mu-\lambda \mu_{J(t)}\right) t+\sigma B_{t}^{H}+\sigma B_{t}-\frac{1}{2} \sigma^{2} t\right. \\
\left.-\frac{1}{2} \sigma^{2} t^{2 H}+\sum_{i=1}^{N_{t}} J\left(t_{i}\right)\right] .
\end{gathered}
$$

By applying the Ito formula for jump diffusion process [55] we have

$$
\begin{aligned}
d V\left(t, S_{t}\right)= & \frac{\partial V}{\partial t}+\frac{1}{2} \sigma^{2} S_{t}^{2} \frac{\partial^{2} V}{\partial S_{t}^{2}}+H \sigma^{2} t^{2 H-1} S_{t}^{2} \frac{\partial^{2} V}{\partial S_{t}^{2}} \\
& +\left(\mu-\lambda \mu_{J(t)}\right) S_{t} \frac{\partial V}{\partial S_{t}}+\sigma S_{t} \frac{\partial V}{\partial S_{t}} d B_{t}+\sigma S_{t} \frac{\partial V}{\partial S_{t}} d B_{t}^{H} \\
& +\left[V\left(e^{J(t)} S_{t}, t\right)-V\left(S_{t}, t\right)\right] d N_{t} .
\end{aligned}
$$

The term of $\left[V\left(e^{J(t)} S_{t}, t\right)-V\left(S_{t}, t\right)\right] d N_{t}$ describes the difference in the option value when a jump occurs. The change in the portfolio value can be expressed as follows:

$$
\begin{aligned}
d \Pi_{t}= & d V\left(t, S_{t}\right) \\
= & \frac{\partial V}{\partial t}+\frac{1}{2} \sigma^{2} S_{t}^{2} \frac{\partial^{2} V}{\partial S_{t}^{2}}+H \sigma^{2} t^{2 H-1} S_{t}^{2} 2 \frac{\partial^{2} V}{\partial S_{t}^{2}} \\
& +\left(\mu-\lambda \mu_{J(t)}\right) S_{t} \frac{\partial V}{\partial S_{t}}+\sigma S_{t} \frac{\partial V}{\partial S_{t}} d B_{t} \\
& +\sigma S_{t} \frac{\partial V}{\partial S_{t}} d B_{t}^{H}+\left[V\left(e^{J(t)} S_{t}, t\right)-V\left(S_{t}, t\right)\right] d N_{t} \\
& -\Delta\left[S_{t}\left(\mu-\lambda \mu_{J(t)}\right) d t+\sigma S_{t} d B_{t}+\sigma S_{t} d B_{t}^{H}\right. \\
d \Pi_{t}= & \quad \frac{\partial V}{\partial t}+\frac{1}{2} \sigma^{2} S_{t}^{2} \frac{\partial^{2} V}{\partial S_{t}^{2}}+H \sigma^{2} t^{2 H-1} S_{t}^{2} \frac{\partial^{2} V}{\partial S_{t}^{2}} \\
& \left.+\left(\mu-\lambda \mu_{J(t)}\right) S_{t} \frac{\partial V}{\partial S_{t}}-\Delta\left(\mu-\lambda \mu_{J(t)}\right) S_{t}\right] d t \\
& +\left(\sigma S_{t} \frac{\partial V}{\partial S_{t}}-\Delta \sigma S_{t}\right) d B_{t}+\left(\sigma S_{t} \frac{\partial V}{\partial S_{t}}-\Delta \sigma S_{t}\right) d B_{t}^{H} \\
& +\left[V\left(e^{J(t)} S_{t}, t\right)-V\left(S_{t}, t\right)-\Delta S_{t}\left(e^{J(t)}-1\right)\right] d N_{t} .
\end{aligned}
$$

By setting $\Delta=\partial V / \partial S_{t}$ to eliminate the stochastic noise, then

$$
\begin{array}{r}
d \Pi_{t}=\left(\frac{\partial V}{\partial t}+\frac{1}{2} \sigma^{2} S_{t}^{2} \frac{\partial^{2} V}{\partial S_{t}^{2}}+H \sigma^{2} t^{2 H-1} S_{t}^{2} \frac{\partial^{2} V}{\partial S_{t}^{2}}\right. \\
+\lambda E\left[V\left(e^{J(t)} S_{t}, t\right)-V\left(S_{t}, t\right)\right. \\
\left.\left.-\frac{\partial V}{\partial S_{t}}\left(e^{J(t)}-1\right) S_{t}\right]\right) d t
\end{array}
$$

The return of an amount $\Pi_{t}$ invested in bank account is equal to $r_{d} \Pi_{t} d t$ at time $d t$. For absence of arbitrage these values must be the same [43].

Proof of Theorem 11. First, we derive a general formula. Let $y$ be one of the influence factors. By setting

$$
\begin{aligned}
C_{1}\left(t, S_{t}\right)= & S_{t} \prod_{i=1}^{n} e^{J\left(t_{i}\right)} e^{-\left(r_{f}+\lambda \mu_{J(t)}\right)(T-t)} N\left(d_{1}\right) \\
& -K e^{-r_{d}(T-t)} N\left(d_{2}\right),
\end{aligned}
$$


then we have

$$
\begin{aligned}
\frac{\partial C_{1}}{\partial y}= & \frac{\partial\left(S_{t} \prod_{i=1}^{n} e^{J\left(t_{i}\right)} e^{-\left(r_{f}+\lambda \mu_{J(t)}\right)(T-t)}\right)}{\partial y} N\left(d_{1}\right) \\
& +S_{t} \prod_{i=1}^{n} e^{J\left(t_{i}\right)} e^{-\left(r_{f}+\lambda \mu_{J(t)}\right)(T-t)} \frac{\partial N\left(d_{1}\right)}{\partial y} \\
& -\frac{\partial K e^{-r_{d}(T-t)}}{\partial y} N\left(d_{2}\right)-K e^{-r_{d}(T-t)} \frac{\partial N\left(d_{2}\right)}{\partial y} .
\end{aligned}
$$

But

$$
\begin{aligned}
& \frac{\partial N\left(d_{2}\right)}{\partial y} \\
& =N^{\prime}\left(d_{2}\right) \frac{\partial d_{2}}{\partial y} \\
& =\frac{1}{\sqrt{2 \pi}} e^{-d_{2}^{2} / 2} \frac{\partial d_{2}}{\partial y} \\
& =\frac{1}{\sqrt{2 \pi}} \exp \left[-\left(d_{1}-\left(\sigma^{2}(T-t)\right.\right.\right. \\
& \left.\left.\left.+\sigma^{2}\left(T^{2 H}-t^{2 H}\right)\right)^{1 / 2}\right)^{2} / 2\right] \frac{\partial d_{2}}{\partial y} . \\
& =\frac{1}{\sqrt{2 \pi}} e^{-d_{2}^{2} / 2} \exp \left[d_{1} \sqrt{\sigma^{2}(T-t)+\sigma^{2}\left(T^{2 H}-t^{2 H}\right)}\right] \\
& \times \exp \left[-\frac{\sigma^{2}(T-t)+\sigma^{2}\left(T^{2 H}-t^{2 H}\right)}{2}\right] \frac{\partial d_{2}}{\partial y} \\
& =\frac{1}{\sqrt{2 \pi}} e^{-d_{2}^{2} / 2} \exp \left[\ln \left(\frac{S_{t} \prod_{i=1}^{n} e^{J\left(t_{i}\right)}}{K}\right)\right. \\
& \left.+\left(r_{d}-r_{f}-\lambda \mu_{J(t)}\right)(T-t)\right] \frac{\partial d_{2}}{\partial y} \\
& =N^{\prime}\left(d_{1}\right) \frac{S_{t} \prod_{i=1}^{n} e^{J\left(t_{i}\right)}}{K} \\
& \times \exp \left[\left(r_{d}-r_{f}-\lambda \mu_{J(t)}\right)(T-t)\right] \frac{\partial d_{2}}{\partial y} .
\end{aligned}
$$

Then we have

$$
\begin{aligned}
\frac{\partial C_{1}}{\partial y} & \\
= & \frac{\partial\left(S_{t} \prod_{i=1}^{n} e^{J\left(t_{i}\right)} e^{-\left(r_{f}+\lambda \mu_{J(t)}\right)(T-t)}\right)}{\partial y} N\left(d_{1}\right) \\
& -\frac{\partial K e^{-r_{d}(T-t)}}{\partial y} N\left(d_{2}\right)
\end{aligned}
$$

$$
\begin{aligned}
& +S_{t} \prod_{i=1}^{n} e^{J\left(t_{i}\right)} e^{-\left(r_{f}+\lambda \mu_{J(t)}\right)(T-t)} N^{\prime}\left(d_{1}\right) \\
& \times \frac{\partial \sqrt{\sigma^{2}(T-t)+\sigma^{2}\left(T^{2 H}-t^{2 H}\right)}}{\partial y} .
\end{aligned}
$$

Substituting in (A.23) we get the desired.

Proof of Theorem 12. We first differentiate $C\left(t, S_{t}\right)$ with respect to $H$; then we have

$$
\begin{aligned}
& \frac{\partial C}{\partial H}=\sum_{n=0}^{\infty} \frac{e^{-\lambda(T-t)} \lambda^{n}(T-t)^{n}}{n !} \varepsilon_{n} \\
& \times\left[S_{t} \prod_{i=1}^{n} e^{J\left(t_{i}\right)} e^{-\left(r_{f}+\lambda \mu_{J(t)}\right)(T-t)} N^{\prime}\left(d_{1}\right)\right. \\
& \left.\times \frac{\partial \sqrt{\sigma^{2}(T-t)+\sigma^{2}\left(T^{2 H}-t^{2 H}\right)}}{\partial H}\right] \\
& =\sum_{n=0}^{\infty} \frac{e^{-\lambda(T-t)} \lambda^{n}(T-t)^{n}}{n !} \varepsilon_{n} \\
& \times\left[S_{t} \prod_{i=1}^{n} e^{J\left(t_{i}\right)} e^{-\left(r_{f}+\lambda \mu_{J(t)}\right)(T-t)} N^{\prime}\left(d_{1}\right)\right. \\
& \left.\times \frac{\sigma^{2}\left(T^{2 H} \ln T-t^{2 H} \ln t\right)}{\sqrt{\sigma^{2}(T-t)+\sigma^{2}\left(T^{2 H}-t^{2 H}\right)}}\right] .
\end{aligned}
$$

\section{Conflict of Interests}

The authors declare that there is no conflict of interests regarding the publication of this paper.

\section{Acknowledgment}

The authors express their sincere thanks to the referees for the careful and detailed reading of the paper and very helpful suggestions. The authors gratefully acknowledge that this research was partially supported by the University Putra Malaysia under the GP-IBT Grant Scheme having project no. GP-IBT/2013/9420100.

\section{References}

[1] A. Dravid, M. Richardson, and T. Sun, "Pricing foreign index contingent claims: an application to Nikkei index warrants," Journal of Derivatives, vol. 1, no. 1, pp. 33-51, 1993.

[2] T. S. Ho, R. C. Stapleton, and M. G. Subrahmanyam, "Correlation risk, crossmarket derivative products and portfolio performance," Journal of European Financial Management, vol. 1, no. 2, pp. 105-124, 1995. 
[3] K. B. Toft and E. S. Reiner, "Currency-translated foreign equity options: the American case," Advances in Futures and Options Research, vol. 9, article 13, pp. 233-264, 1997.

[4] Y. K. Kwok and H. Y. Wong, "Currency-translated foreign equity options with path dependent features and their multi-asset extensions," International Journal of Theoretical and Applied Finance, vol. 3, no. 2, pp. 257-278, 2000.

[5] J. ] Duan and J. Wei, "Pricing foreign-currency and crosscurrency options under GARCH," Journal of Derivatives, vol. 7, no. 1, pp. 51-63, 1999.

[6] M. B. Garman and S. W. Kohlhagen, "Foreign currency option values," Journal of International Money and Finance, vol. 2, no. 3, pp. 231-237, 1983.

[7] R. Cookson, "Models of imperfection," Risk, vol. 9, no. 5, pp. 55-60, 1992.

[8] N. Ekvall, L. P. Jennergren, and B. Näslund, "Currency option pricing with mean reversion and uncovered interest parity: a revision of the Garman-Kohlhagen model," European Journal of Operational Research, vol. 100, no. 1, pp. 41-59, 1997.

[9] J. V. Rosenberg, "Pricing multivariate contingent claims using estimated risk-neutral density functions," Journal of International Money and Finance, vol. 17, no. 2, pp. 229-247, 1998.

[10] G. Sarwar and T. Krehbiel, "Empirical performance of alternative pricing models of currency options," Journal of Futures Markets, vol. 20, no. 3, pp. 265-291, 2000.

[11] N. P. B. Bollen and E. Rasiel, "The performance of alternative valuation models in the OTC currency options market," Journal of International Money and Finance, vol. 22, no. 1, pp. 33-64, 2003.

[12] P. Jorion, "On jump processes in the foreign exchange and stock markets," Review of Financial Studies, vol. 1, no. 4, pp. 427-445, 1988.

[13] D. S. Bates, "Dollar jump fears, 1984-1992: distributional abnormalities implicit in currency futures options," Journal of International Money and Finance, vol. 15, no. 1, pp. 65-93, 1996.

[14] D. S. Bates, "Jumps and stochastic volatility: exchange rate processes implicit in deutsche mark options," Review of Financial Studies, vol. 9, no. 1, pp. 69-107, 1996.

[15] M. Chernov, A. R. Gallant, E. Ghysels, and G. Tauchen, "Alternative models for stock price dynamics," Journal of Econometrics, vol. 116, no. 1-2, pp. 225-257, 2003.

[16] J. Pan, "The jump-risk premia implicit in options: evidence from an integrated time-series study," Journal of Financial Economics, vol. 63, no. 1, pp. 3-50, 2002.

[17] B. Eraker, "Do stock prices and volatility jump? Reconciling evidence from spot and option prices," Journal of Finance, vol. 59, no. 3, pp. 1367-1403, 2004.

[18] R. C. Merton, "Option pricing when underlying stock returns are discontinuous," Journal of Financial Economics, vol. 3, no. 1-2, pp. 125-144, 1976.

[19] S. G. Kou, "A jump-diffusion model for option pricing," Management Science, vol. 48, no. 8, pp. 1086-1101, 2002.

[20] R. Cont and P. Tankov, "Non-parametric calibration of jumpdiffusion option pricing models," Journal of Computational Finance, vol. 7, no. 3, pp. 1-49, 2004.

[21] A. W. Lo, "Long-term memory in stock market prices," Econometrical, vol. 59, no. 5, pp. 1279-1313, 1991.

[22] R. N. Mantegna and H. E. Stanley, An Introduction to Econophysics, Cambridge University Press, Cambridge, UK, 2007.
[23] B. Huang and C. W. Yang, "The fractal structure in multinational stock returns," Applied Economics Letters, vol. 2, pp. 67-71, 1995.

[24] D. O. Cajueiro and B. M. Tabak, "Long-range dependence and multifractality in the term structure of LIBOR interest rates," Physica A, vol. 373, pp. 603-614, 2007.

[25] S. H. Kang and S.-M. Yoon, "Long memory properties in return and volatility: evidence from the Korean stock market," Physica A, vol. 385, no. 2, pp. 591-600, 2007.

[26] S. H. Kang and S.-M. Yoon, "Long memory features in the high frequency data of the Korean stock market," Physica A, vol. 387, no. 21, pp. 5189-5196, 2008.

[27] S. H. Kang, C. Cheong, and S.-M. Yoon, "Long memory volatility in Chinese stock markets," Physica A, vol. 389, no. 7, pp. 1425-1433, 2010.

[28] Y. Wang, Y. Wei, and C. Wu, "Cross-correlations between Chinese A-share and B-share markets," Physica A, vol. 389, no. 23, pp. 5468-5478, 2010.

[29] Z. Ding, C. W. J. Granger, and R. F. Engle, "A long memory property of stock market returns and a new model," Journal of Empirical Finance, vol. 1, no. 1, pp. 83-106, 1993.

[30] Y. Liu, P. Gopikrishnan, P. Cizeau, M. Meyer, C.-K. Peng, and H. E. Stanley, "The statistical properties of the volatility of price fluctuations," Physical Review E, vol. 60, no. 2, pp. 1390-1400, 1999.

[31] B. Podobnik and H. E. Stanley, "Detrended cross-correlation analysis: a new method for analyzing two nonstationary time series," Physical Review Letters, vol. 100, no. 8, Article ID 084102, 2008.

[32] B. Podobnik, D. Horvatic, A. M. Petersen, and H. E. Stanley, "Cross-correlations between volume change and price change," Proceedings of the National Academy of Sciences of the United States of America, vol. 106, no. 52, pp. 22079-22084, 2009.

[33] A. Carbone, G. Castelli, and H. E. Stanley, "Time-dependent hurst exponent in financial time series," Physica A, vol. 344, no. 1-2, pp. 267-271, 2004.

[34] X.-T. Wang, E.-H. Zhu, M.-M. Tang, and H.-G. Yan, "Scaling and long-range dependence in option pricing II: pricing European option with transaction costs under the mixed Brownianfractional Brownian model," Physica A, vol. 389, no. 3, pp. 445$451,2010$.

[35] X.-T. Wang, "Scaling and long range dependence in option pricing, IV: pricing European options with transaction costs under the multifractional Black-Scholes model," Physica A, vol. 389, no. 4, pp. 789-796, 2010.

[36] X.-T. Wang, M. Wu, Z.-M. Zhou, and W.-S. Jing, "Pricing European option with transaction costs under the fractional long memory stochastic volatility model," Physica A, vol. 391, no. 4, pp. 1469-1480, 2012.

[37] W. Xiao, W. Zhang, W. Xu, and X. Zhang, "The valuation of equity warrants in a fractional Brownian environment," Physica A, vol. 391, no. 4, pp. 1742-1752, 2012.

[38] W. Xiao, W. Zhang, and W. Xu, "Parameter estimation for fractional Ornstein-Uhlenbeck processes at discrete observation," Applied Mathematical Modelling, vol. 35, no. 9, pp. 4196-4207, 2011.

[39] T. Björk and H. Hult, "A note on Wick products and the fractional Black-Scholes model," Finance and Stochastics, vol. 9, no. 2, pp. 197-209, 2005.

[40] R. J. Elliott and J. van der Hoek, "A general fractional white noise theory and applications to finance," Mathematical Finance, vol. 13, no. 2, pp. 301-330, 2003. 
[41] C. El-Nouty, "The fractional mixed fractional Brownian motion," Statistics and Probability Letters, vol. 65, no. 2, pp. 111120, 2003.

[42] Y. Mishura, Stochastic Calculus for Fractional Brownian Motions and Related Processes, Springer, 2008.

[43] L. Sun, "Pricing currency options in the mixed fractional Brownian motion," Physica A, vol. 392, no. 16, pp. 3441-3458, 2013.

[44] W. Xiao, W. Zhang, W. Xu, and X. Zhang, "The valuation of equity warrants in a fractional Brownian environment," Physica A, vol. 391, no. 4, pp. 1742-1752, 2012.

[45] P. Cheridito, "Arbitrage in fractional Brownian motion models," Finance and Stochastics, vol. 7, no. 4, pp. 533-553, 2003.

[46] Y. Mishura, Stochastic Calculus for Fractional Brownian Motions and RelatedProcesses, Springer, Berlin, Germany, 2008.

[47] M. C. Mariani, I. Florescu, M. P. Beccar Varela, and E. Ncheuguim, "Study of memory effects in international market indices," Physica A, vol. 389, no. 8, pp. 1653-1664, 2010.

[48] F. Serinaldi, "Use and misuse of some Hurst parameter estimators applied to stationary and non-stationary financial time series," Physica A, vol. 389, no. 14, pp. 2770-2781, 2010.

[49] Y.-P. Ruan and W.-X. Zhou, "Long-term correlations and multifractal nature in the intertrade durations of a liquid Chinese stock and its warrant," Physica A, vol. 390, no. 9, pp. 1646-1654, 2011.

[50] Y. Wang, Y. Wei, and C. Wu, "Detrended fluctuation analysis on spot and futures markets of West Texas Intermediate crude oil," Physica A, vol. 390, no. 5, pp. 864-875, 2011.

[51] L.-Y. He and W.-B. Qian, "A Monte Carlo simulation to the performance of the R/S and V/S methods-statistical revisit and real world application," Physica A, vol. 391, no. 14, pp. 3770-3782, 2012.

[52] W.-L. Xiao, W.-G. Zhang, X.-L. Zhang, and Y.-L. Wang, "Pricing currency options in a fractional Brownian motion with jumps," Economic Modelling, vol. 27, no. 5, pp. 935-942, 2010.

[53] Y. Hu and B. Øksendal, "Fractional white noise calculus and applications to finance," Infinite Dimensional Analysis, Quantum Probability and Related Topics, vol. 6, no. 1, pp. 1-32, 2003.

[54] M. Zili, "On the mixed fractional Brownian motion," Journal of Applied Mathematics and Stochastic Analysis, vol. 2006, Article ID 32435, 9 pages, 2006.

[55] Kazuhisa Matsuda, Introduction to Merton Jump Diffusion Model, Department of Economics, The Graduate Center, The City University of New York. 


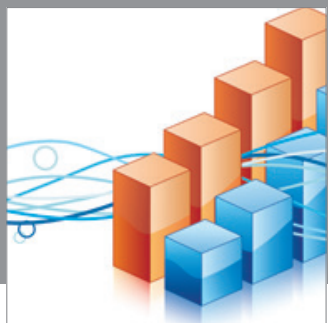

Advances in

Operations Research

mansans

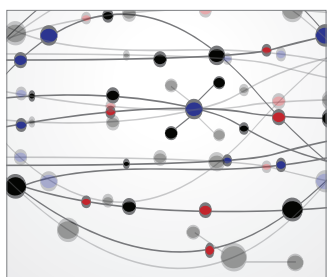

The Scientific World Journal
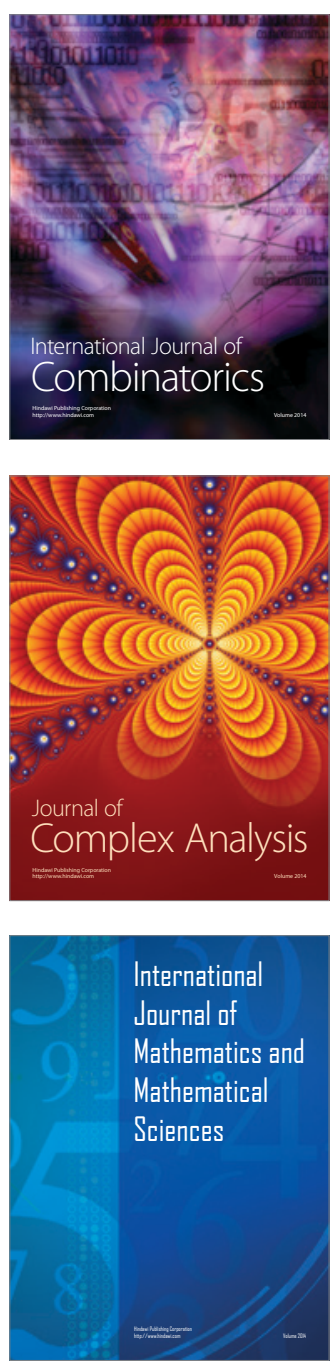
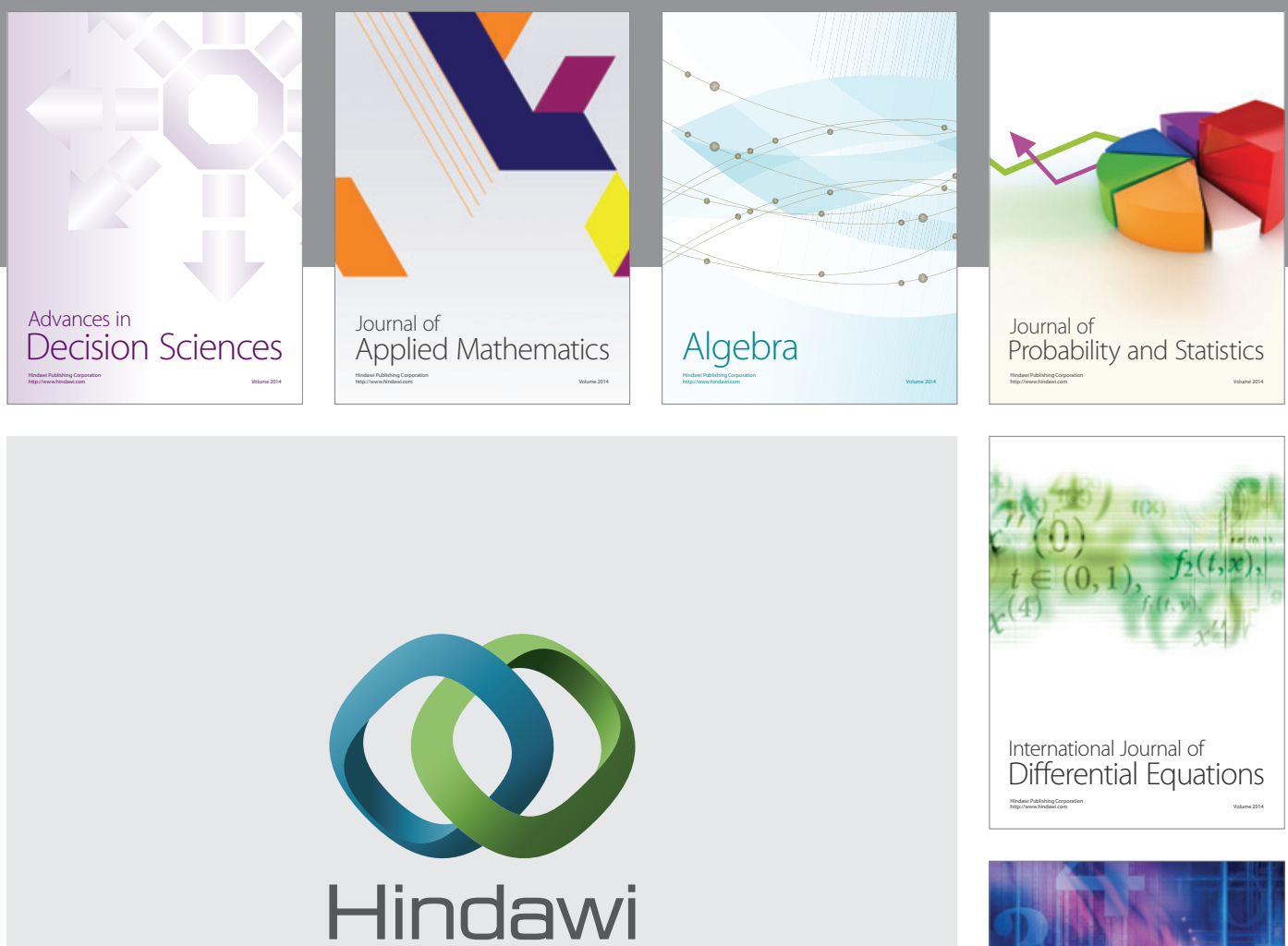

Submit your manuscripts at http://www.hindawi.com
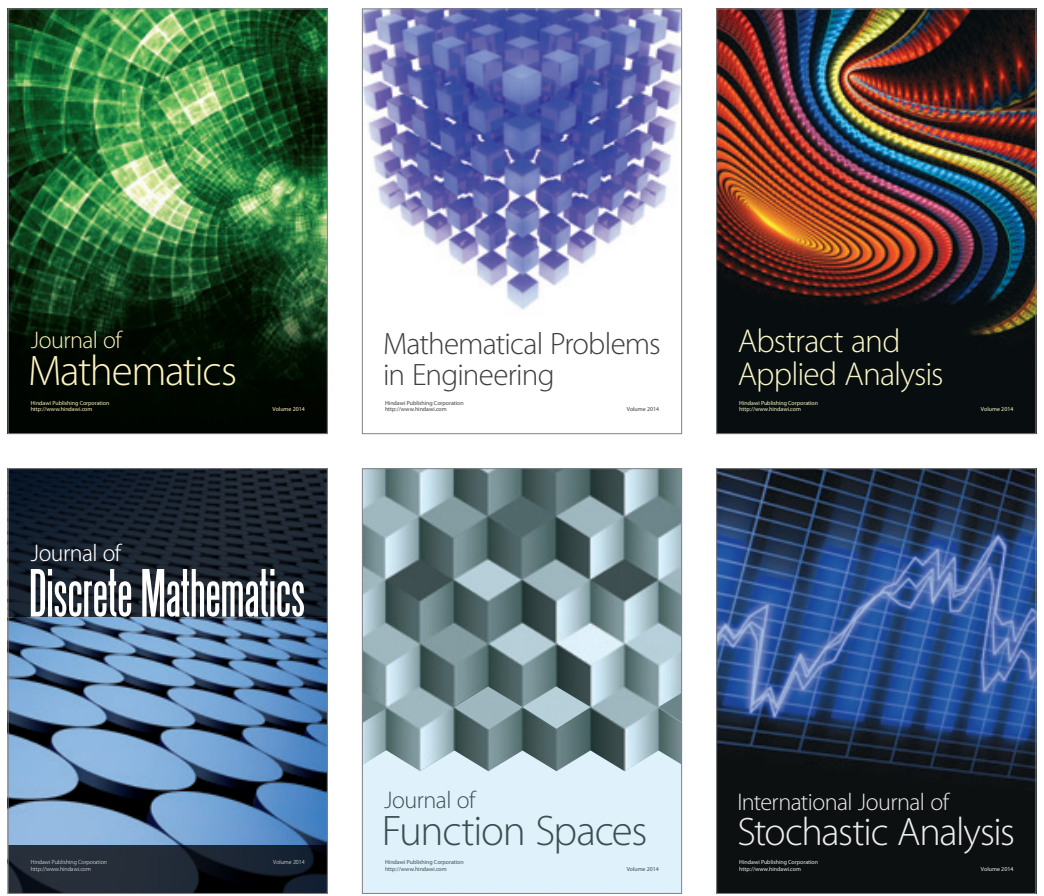

Journal of

Function Spaces

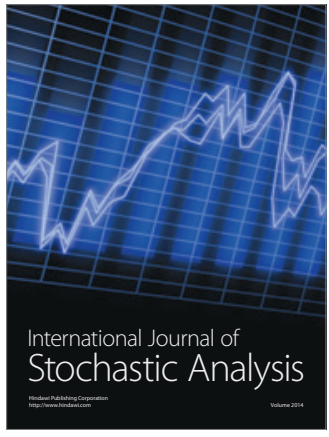

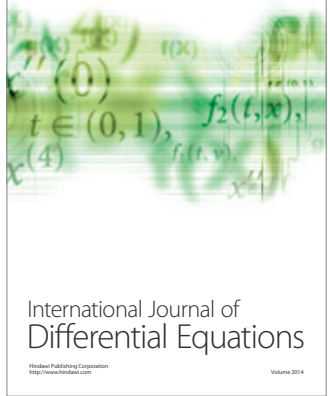
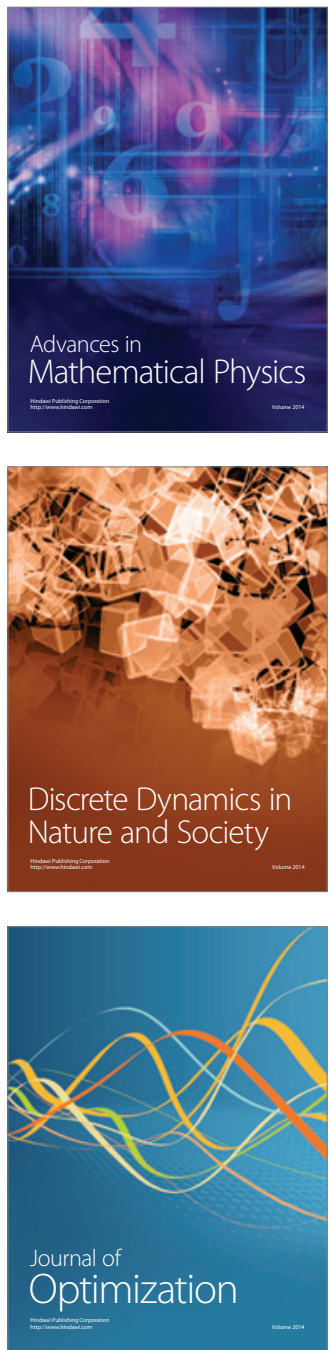